\title{
Time course of blood pressure control prior to lacunar TIA and stroke
}

Population-based study

Linxin Li, DPhil, Sarah J.V. Welch, RGN, Sergei A. Gutnikov, DPhil, Ziyah Mehta, DPhil, and Peter M. Rothwell, FMedSci, on behalf of the Oxford Vascular Study

Neurology ${ }^{\circledR}$ 2018;90:e1732-e1741. doi:10.1212/WNL.0000000000005526

\section{Abstract}

\section{Objective}

To determine the age-specific temporal trends in blood pressure (BP) before acute lacunar vs nonlacunar TIA and stroke.

\section{Methods}

In a population-based study of TIA/ischemic stroke (Oxford Vascular Study), we studied 15year premorbid BP readings from primary care records in patients with lacunar vs nonlacunar events (Trial of Org 10172 in Acute Stroke Treatment [TOAST]) stratified by age $(<65, \geq 65$ years).

\section{Results}

Of 2,085 patients (1,250 with stroke, 835 with TIA), 309 had lacunar events. In 493 patients $<65$ years of age, the prevalence of diagnosed hypertension did not differ between lacunar and nonlacunar events $(46[48.4 \%]$ vs $164[41.2 \%], p=0.20)$, but mean/SD premorbid BP $(44,496$ $\mathrm{BP}$ readings) was higher in patients with lacunar events (15-year records: systolic BP [SBP] $138.5 / 17.7$ vs $133.3 / 15.0 \mathrm{~mm} \mathrm{Hg}, p=0.004$; diastolic $\mathrm{BP}[\mathrm{DBP}] 84.1 / 9.6$ vs $80.9 / 8.4 \mathrm{~mm} \mathrm{Hg}$, $p=0.001$ ), mainly because of higher mean BP during the 5 years before the event (SBP 142.6) 18.8 vs $134.6 / 16.6 \mathrm{~mm} \mathrm{Hg}, p=0.0001$; DBP 85.2/9.7 vs 80.6/9.0 $\mathrm{mm} \mathrm{Hg}, p<0.0001$ ), with a rising trend $\left(p_{\text {trend }}=0.006\right)$ toward higher BP leading up to the event $(<30$-day pre-event SBP: $152.7 / 16.1$ vs $135.3 / 23.1 \mathrm{~mm} \mathrm{Hg}, p=0.009$; DBP 87.9/9.4 vs 80.8/12.8 mm Hg, $p=0.05$; mean $\mathrm{BP} \leq 1$ year before the event $145.8 / 22.0$ vs $134.7 / 16.1 \mathrm{~mm} \mathrm{Hg}, p=0.001 ; 86.1 / 10.7$ vs $80.4 / 9.8 \mathrm{~mm} \mathrm{Hg}, p=0.0001$ ). Maximum BP in the 5 years before the event was also higher in patients with lacunar events (SBP 173.7/26.6 vs 158.6/23.2 mm Hg, $p=0.0001$; DBP 102.3/ 12.9 vs $94.2 / 11.2 \mathrm{~mm} \mathrm{Hg}, p<0.0001)$, as was persistently elevated BP $(\geq 50 \% \mathrm{SBP}>160 \mathrm{~mm} \mathrm{Hg}$, odd ratio $4.95,95 \%$ confidence interval 1.99-12.31, $p=0.0002)$. However, no similar differences in BP were observed in patients $\geq 65$ years of age.

\section{Conclusion}

Recent premorbid BP control is strongly temporarily related to acute lacunar events at younger ages, suggesting a direct role of BP in accelerating causal pathology and highlighting the need to control hypertension quickly.

\author{
Correspondence \\ Dr. Rothwell \\ Peter.rothwell@ \\ ndcn.ox.ac.uk
}

\section{- CME Course \\ NPub.org/cmelist}

\section{RELATED ARTICLE}

\section{Editorial}

Effective stroke prevention requires timely detection and smooth control of hypertension

Page 907 


\section{Glossary}

BP = blood pressure; $\mathbf{C V}=$ coefficient of variation; $\mathbf{D B P}=$ diastolic blood pressure; OXVASC = Oxford Vascular Study; SBP = systolic blood pressure; SPS3 = Secondary Prevention of Small Subcortical Strokes; TOAST = Trial of Org 10172 in Acute Stroke Treatment.

Usual blood pressure (BP) is a well-established risk factor for stroke. ${ }^{1-4}$ However, there is conflicting evidence of the direct role of BP in the etiology of lacunar stroke. While some studies found that previous hypertension was most common in patients with lacunar stroke ${ }^{5-7}$ and that it is predicts recurrent stroke most strongly in lacunar patients, ${ }^{8}$ others suggested an equal prevalence of hypertension and population-attributable fraction in lacunar vs nonlacunar stroke. ${ }^{9,10}$ However, most previous studies were hospital based; the majority used only history of diagnosed hypertension or a single BP often taken some years before the event or after the event $\mathrm{t}^{5-10}$; many included old or silent lacune on brain imaging ${ }^{11-13}$; and none studied the temporal change of $\mathrm{BP}$ leading up to the event.

In a previous study, we showed that deep intracerebral hemorrhage was more closely associated with a recent increase of premorbid BP than lobar intracerebral hemorrhage, and we previously hypothesized that the same might also be true for lacunar vs nonlacunar ischemic stroke. ${ }^{14}$ It is likely, however, that any such temporal trends in premorbid BP in lacunar events will be most marked at younger ages, as has been shown for the overall association between BP and small vessel disease ${ }^{15,16}$ and as is suggested by the strong association with hypertension in the early autopsy studies done predominantly in young patients with lacunar stroke, ${ }^{17}$ whereas a higher rate of chronic arteriosclerotic or atheromatous pathology would be expected at older ages. ${ }^{18}$

In the absence of similar previous studies, we therefore aimed to determine the age-specific temporal trends in BP before acute lacunar vs nonlacunar TIA and ischemic stroke using 15-year premorbid BP measurements from primary care records in a population-based cohort.

\section{Methods}

The Oxford Vascular Study (OXVASC) is an ongoing population-based study of the incidence and outcome of all acute vascular events. ${ }^{19}$ The study population comprises all 92,728 individuals, regardless of age, registered with $\approx 100$ general practitioners in 9 general practices in Oxfordshire, $\mathrm{UK}^{20}$ The multiple overlapping methods used to achieve near-complete ascertainment of all individuals with TIA or ischemic stroke are detailed in the supplemental data (e-methods, links.lww.com/WNL/A447) and have been reported previously. ${ }^{19,20}$ This analysis includes consecutive cases with a first TIA or ischemic stroke from April 1, 2002, to March 31, 2014.
Demographic data; vascular risk factors (previous hypertension, previous diabetes mellitus, previous atrial fibrillation, history of smoking, previous hyperlipidemia); history of cerebrovascular, coronary, or peripheral vascular disease; family history of stroke; and premorbid use of preventive treatment (antiplatelet agent, anticoagulation, lipid-lowering drug, and antihypertensive agent) were collected from face-to-face interview and cross-referenced with primary care records. ${ }^{20}$ Detailed clinical history was recorded in all patients, including the first postevent BP. Patients routinely had CT or MRI brain imaging, intracranial and extracranial vascular imaging, 12lead ECG, and standard blood tests. Transthoracic echocardiography and long-term cardiac monitoring (e.g., 24-hour or 5-day ambulatory ECG) were done when clinically indicated. ${ }^{20}$ All cases were reviewed by a senior neurologist (P.M.R.), and stroke etiology was classified according to the modified Trial of Org 10172 in Acute Stroke Treatment (TOAST) criteria. ${ }^{20,21}$ Acute lacunar events were classified only in patients with no evidence of large artery, cardioembolic, or other rare etiology but fulfilled either imaging evidence of a single and clinically relevant acute subcortical infarction $<20 \mathrm{~mm}$, including acute lacunar lesion within the territory of brainstem penetrating arteries or clinical lacunar syndrome with no cerebral cortical dysfunction and normal $\mathrm{CT} / \mathrm{MRI}$. Given the potential for bias, risk factors such as hypertension and diabetes mellitus were not included in the criteria of lacunar events. ${ }^{9}$

Study nurses reviewed lifelong patient records held in primary care and extracted all premorbid BP readings with dates up to 15 years before the event in a standardized manner. We extracted data from both paper and computer records. Most readings were taken in the doctor's surgery by the physician or the practice nurse for screening purposes, regular review, or an episode of minor illness. Measurements made during previous hospital admissions, often for major illness, were not recorded. We also excluded measurements made in primary care at the time of any previous TIA or stroke. ${ }^{14}$

\section{Statistical analyses}

Values are reported as absolute numbers with percentages for categorical variables and as means with SDs for continuous variables.

Premorbid BP measurements were presented as long-term average BP (mean BP taking into account all measurements before defined time points in patients with at least 1 premorbid BP measurement) and long-term BP variability (calculated in patients who had $\geq 4$ premorbid BP measurements 
and presented as maximum $\mathrm{BP}$, coefficient of variation $[\mathrm{CV}$; $100 \times \mathrm{SD} /$ mean], and percentages of $\mathrm{BP} \geq 50 \%$ above the target [systolic BP (SBP) 140/160/180 mm Hg; diastolic BP (DBP) 90/100/110 mm Hg]).

All analyses were stratified by age $<65$ and $\geq 65$ years. We first compared the frequency of previous hypertension and premorbid use of antihypertensive agents in patients with lacunar vs nonlacunar events using the $\chi^{2}$ test. We then compared the acute postevent BPs and the long-term average BP (15year mean $\mathrm{BP}$, mean $\mathrm{BP} \leq 5$ years before the event, mean $\mathrm{BP}$ $>5$ years before the event) in patients with lacunar vs nonlacunar events using the $t$ test. Trend of long-term BP change over time (i.e., $>10,5-10,1-5$, and $\leq 1$ year and $\leq 30$ days) in patients with lacunar vs nonlacunar events was assessed with the mixed regression model, and we identified any evidence of a systematic rise in BP during the year before the event using regression analysis of the most recent premorbid $\mathrm{BP}$ vs the log of the time from the BP measurement to the index event, stratified by event type (i.e., lacunar vs nonlacunar). We also compared the long-term maximum BP and CV $(\leq 5$ and 15 years before the event) in patients with lacunar vs nonlacunar events using the $t$ test. Proportions of patients with premorbid uncontrolled BP using different target levels were also compared in patients with lacunar vs nonlacunar events with the $\chi^{2}$ test.

Sensitivity analyses stratified by premorbid use of antihypertensive agent, excluding TIA cases, confined to first-ever-in-alifetime incident events and only in patients who had at least $1 \mathrm{BP}$ measurement taken at each time period before the event were also performed.

All analyses were performed with SPSS version 20.

\section{Standard protocol approvals, registrations, and patient consents}

Written informed consent or assent from relatives was obtained in all participants. OXVASC was approved by the local research ethics committee (OREC A: 05/Q1604/70).

\section{Data availability}

Requests for access to data from OXVASC will be considered by the corresponding author.

\section{Results}

Among 2,555 patients with first-in-the-study-period TIA or ischemic stroke, 331 (12.9\%) had events of unknown etiology due to incomplete investigation before death and 90 (3.5\%) had multiple etiologies identified after the diagnostic workup and were therefore excluded from the current analysis. Among the remaining 2,134 patients, 2,085 (97.7\%; 1,250 stroke, 835 TIA; 309 lacunar events; 493 with age $<65$ years) had at least 1 premorbid BP recorded (median occasions on which BP measured per patient 16, interquartile range $7-32$ ), with 44,496 premorbid BP measurements in total.

Table 1 summarizes the baseline characteristics of patients with lacunar vs nonlacunar events stratified by age. For patients $<65$ years of age, known atrial fibrillation and premorbid use of anticoagulants were less common in lacunar vs nonlacunar events, but there were no significant differences in other vascular risk factors or premorbid use of preventive treatment (table 1), including in the prevalence of diagnosed hypertension (46 [48.4\%] vs 164 [41.2\%], $p=0.20$; table 1 ) and premorbid use of antihypertensive agents $(32[33.7 \%]$ vs 137 [34.4\%], $p=0.89$; table 1 ). Among patients $\geq 65$ years of age, those with lacunar events were younger, had less known atrial fibrillation, previous myocardial infarction, and premorbid use of anticoagulants, and more often were current smokers (table 1), but the prevalence of diagnosed hypertension was again similar in lacunar vs nonlacunar events (139 [65.0\%] vs 962 [69.8\%], $p=0.15$; table 1 ), although fewer patients with lacunar events were on premorbid antihypertensive treatment (119 [55.6\%] vs $932[67.6 \%], p=0.001$; table 1).

Despite the similar prevalence of diagnosed hypertension in patients with lacunar vs nonlacunar events, for patients $<65$ years of age, the 15-year mean/SD BP was significantly higher in those with lacunar events (SBP 138.5/17.7 vs 133.3/ $15.0 \mathrm{~mm} \mathrm{Hg}, p=0.004$; DBP $84.1 / 9.6$ vs $80.9 / 8.4 \mathrm{~mm} \mathrm{Hg}, p=$ 0.001 ; table 2). Moreover, this difference was explained mainly by a higher mean BP $\leq 5$ years before the event in patients with lacunar events (table 2). When the pre-event time periods were further divided, the difference in BP in patients with lacunar vs nonlacunar events increased $\left(p_{\text {trend }}=\right.$ 0.006) with BP measured closer to the index event (figure 1), and the SBP was higher in the weeks and days before (figure 2) and immediately (table 1) after the index event. Sensitivity analyses restricted to patients with at least 1 reading in each time period (table e-1, links.lww.com/WNL/A446), excluding patients with TIA events (table e-2), or confined only to incident events (table e-3) showed consistent results. Trends were also similar in analyses stratified by premorbid use of antihypertensive agents, although it was most prominent in patients on premorbid antihypertensive treatment (15-year mean: SBP $151.8 / 17.7$ vs $141.4 / 14.9 \mathrm{~mm} \mathrm{Hg}, p=0.001$, DBP 91.1/9.6 vs $84.5 / 8.3 \mathrm{~mm} \mathrm{Hg}, p=0.0001 ; \mathrm{BP} \leq 5$ years: $\mathrm{SBP}$ $153.7 / 18.8$ vs $139.7 / 16.3 \mathrm{~mm} \mathrm{Hg}, p<0.0001$, DBP $90.8 / 10.3$ vs $82.3 / 9.3 \mathrm{~mm} \mathrm{Hg}, p<0.0001$; $\mathrm{BP}>5$ years: SBP $140.5 / 14.2$ vs $142.1 / 16.4 \mathrm{~mm} \mathrm{Hg}, p=0.65$, DBP $87.9 / 8.0$ vs $86.2 /$ $8.6 \mathrm{~mm} \mathrm{Hg}, p=0.34$; table e- 4 and figures e- 1 and e-2, links. lww.com/WNL/A445).

In contrast to patients at younger ages, among patients $\geq 65$ years of age, those with lacunar events had similar 15-year mean BP (table 2) or mean BP taken $>5$ years before the event (table 2) compared to those with nonlacunar events. Although the mean DBP taken $\leq 5$ years before the event was marginally higher for patients with lacunar events $(80.8 / 8.3$ vs 
Table 1 Baseline characteristics of patients with lacunar vs nonlacunar events stratified by age

\begin{tabular}{|c|c|c|c|c|c|c|c|c|c|}
\hline & \multicolumn{2}{|l|}{ Age $<65$ y } & \multirow[b]{2}{*}{$p$ Value } & \multicolumn{2}{|l|}{ Age $\geq 65$ y } & \multirow[b]{2}{*}{$p$ Value } & \multirow{2}{*}{$\begin{array}{l}\text { Total } \\
\text { Lacunar } \\
(\mathrm{n}=309)\end{array}$} & \multirow[b]{2}{*}{$\begin{array}{l}\text { Nonlacunar } \\
(n=1,776)\end{array}$} & \multirow[b]{2}{*}{$p$ Value } \\
\hline & $\begin{array}{l}\text { Lacunar } \\
(\mathrm{n}=95)\end{array}$ & $\begin{array}{l}\text { Nonlacunar } \\
(\mathrm{n}=398)\end{array}$ & & $\begin{array}{l}\text { Lacunar } \\
(n=214)\end{array}$ & $\begin{array}{l}\text { Nonlacunar } \\
(n=1,378)\end{array}$ & & & & \\
\hline Age (mean/SD), y & $54.7 / 7.7$ & $54.5 / 8.2$ & 0.81 & $76.6 / 7.5$ & 78.9/7.6 & $<0.0001$ & $69.8 / 12.6$ & $73.4 / 12.7$ & $<0.0001$ \\
\hline Male, n (\%) & $64(67.4)$ & $245(61.6)$ & 0.29 & $112(52.3)$ & $639(46.4)$ & 0.10 & $176(57.0)$ & $884(49.8)$ & 0.02 \\
\hline $\begin{array}{l}\text { History of } \\
\text { hypertension, } n(\%)\end{array}$ & $46(48.4)$ & $164(41.2)$ & 0.20 & $139(65.0)$ & $962(69.8)$ & 0.15 & 185 (59.9) & $1,126(63.4)$ & 0.24 \\
\hline $\begin{array}{l}\text { History of diabetes } \\
\text { mellitus, } \mathbf{n}(\%)\end{array}$ & $15(15.8)$ & 45 (11.3) & 0.23 & $36(16.8)$ & $187(13.6)$ & 0.20 & $51(16.5)$ & $232(13.1)$ & 0.10 \\
\hline $\begin{array}{l}\text { History of atrial } \\
\text { fibrillation, } n(\%)\end{array}$ & $0(0)$ & $42(10.6)$ & 0.001 & $3(1.4)$ & $393(28.5)$ & $<0.0001$ & $3(1.0)$ & $435(24.5)$ & $<0.0001$ \\
\hline $\begin{array}{l}\text { History of } \\
\text { hyperlipidemia, } \mathrm{n}(\%)\end{array}$ & $29(30.5)$ & $125(31.4)$ & 0.87 & 74 (34.6) & $527(38.2)$ & 0.30 & $103(33.3)$ & $652(36.7)$ & 0.25 \\
\hline $\begin{array}{l}\text { History myocardial } \\
\text { infarction, } \mathbf{n}(\%)\end{array}$ & $2(2.1)$ & $22(5.5)$ & 0.16 & $14(6.5)$ & $202(14.7)$ & 0.001 & $16(5.2)$ & $224(12.6)$ & 0.0002 \\
\hline $\begin{array}{l}\text { History of peripheral } \\
\text { vascular disease, } n(\%)\end{array}$ & $2(2.1)$ & $14(3.5)$ & 0.49 & $13(6.1)$ & $116(8.4)$ & 0.24 & $15(4.9)$ & $130(7.3)$ & 0.12 \\
\hline Previous TIA & $2(2.1)$ & $20(5.0)$ & 0.22 & $26(12.1)$ & $140(10.2)$ & 0.38 & $28(9.1)$ & $160(9.0)$ & 0.98 \\
\hline Previous stroke, n (\%) & $8(8.4)$ & $18(4.5)$ & 0.13 & $19(8.9)$ & $157(11.4)$ & 0.28 & $27(8.7)$ & 175 (9.9) & 0.54 \\
\hline $\begin{array}{l}\text { History of smoking, } \\
\mathrm{n}(\%)^{\mathrm{a}}\end{array}$ & $67(70.5)$ & $250(62.8)$ & 0.16 & $123(57.5)$ & $736(53.6)$ & 0.29 & $190(61.5)$ & $986(55.7)$ & 0.06 \\
\hline Current smoker, $\mathrm{n}(\%)^{\mathbf{b}}$ & 36 (37.9) & 127 (31.9) & 0.27 & $37(17.3)$ & $105(7.6)$ & $<0.0001$ & $73(23.6)$ & $232(13.1)$ & $<0.0001$ \\
\hline $\begin{array}{l}\text { Family history of } \\
\text { stroke, } n(\%)^{c}\end{array}$ & 28 (31.8) & $118(31.2)$ & 0.91 & 66 (33.3) & 385 (31.5) & 0.60 & 94 (32.9) & 503 (31.4) & 0.63 \\
\hline $\begin{array}{l}\text { Premorbid } \\
\text { antihypertensive } \\
\text { agents, } \mathrm{n}(\%)\end{array}$ & $32(33.7)$ & $137(34.4)$ & 0.89 & $119(55.6)$ & $932(67.6)$ & 0.001 & $151(48.9)$ & $1,069(60.2)$ & 0.0002 \\
\hline $\begin{array}{l}\text { Single } \\
\text { antihypertensive } \\
\text { agent, } \mathrm{n}(\%)\end{array}$ & 17 (17.9) & $67(16.8)$ & 0.90 & $58(27.1)$ & $332(24.1)$ & $<0.0001$ & 75 (24.3) & $399(22.5)$ & $<0.0001$ \\
\hline $\begin{array}{l}\geq 2 \text { Antihypertensive } \\
\text { agents, } \mathrm{n}(\%)\end{array}$ & $15(15.8)$ & $70(17.6)$ & & $61(28.5)$ & $600(43.5)$ & & $76(24.6)$ & $670(37.7)$ & \\
\hline $\begin{array}{l}\text { Premorbid } \\
\text { anticoagulants, n (\%) }\end{array}$ & $0(0)$ & $21(5.3)$ & 0.02 & $0(0)$ & $90(6.5)$ & 0.0001 & $0(0)$ & $111(6.2)$ & $<0.0001$ \\
\hline $\begin{array}{l}\text { Premorbid } \\
\text { antiplatelet } \\
\text { agents, } \mathrm{n}(\%)\end{array}$ & $18(18.9)$ & $72(18.1)$ & 0.85 & $83(38.8)$ & $628(45.6)$ & 0.06 & $101(32.7)$ & $700(39.4)$ & 0.03 \\
\hline Premorbid statin, $\mathbf{n}(\%)$ & 17 (17.9) & 77 (19.3) & 0.75 & $52(24.3)$ & $428(31.1)$ & 0.05 & $69(22.3)$ & $505(28.4)$ & 0.03 \\
\hline
\end{tabular}

\section{First acute BP after}

the event (mean/

$\mathrm{SD}), \mathrm{mm} \mathrm{Hg}$

\begin{tabular}{|c|c|c|c|c|c|c|c|c|c|}
\hline SBP & $161.0 / 31.6^{d}$ & $145.7 / 24.7^{d}$ & $<0.0001$ & $160.2 / 28.3^{e}$ & $154.6 / 28.7^{e}$ & 0.01 & $160.4 / 29.3$ & $152.6 / 28.1$ & $<0.0001$ \\
\hline DBP & $92.8 / 18.0^{d}$ & $86.1 / 13.8^{d}$ & 0.001 & $84.0 / 13.3^{e}$ & $81.7 / 14.8^{\mathrm{e}}$ & 0.04 & $86.7 / 15.4$ & $82.7 / 14.7$ & $<0.0001$ \\
\hline
\end{tabular}

Abbreviations: $\mathrm{BP}=$ blood pressure; $\mathrm{DBP}=$ diastolic blood pressure; $\mathrm{SBP}=$ systolic blood pressure.

a Five patients with missing data.

${ }^{\mathrm{b}}$ Four patients with missing data.

c One hundred ninety-eight patients with missing data.

${ }^{\mathrm{d}}$ Four patients with missing data for SBP after nonlacunar events and 5 missing data for DBP after nonlacunar events.

e One patient with missing data for SBP and 3 with missing data for DBP after lacunar events; 15 patients with missing data for SBP and 30 with missing data for DBP after nonlacunar events. 
Table 2 Premorbid average BP (mean BP) and BP variability (maximum BP, BP CV, and frequency of high BP readings according to different target levels) in patients with lacunar vs nonlacunar events stratified by age

\begin{tabular}{|c|c|c|c|c|c|c|c|}
\hline & \multicolumn{3}{|l|}{ Age $<65$ y } & \multicolumn{3}{|l|}{ Age $\geq 65 y$} & \multirow[b]{2}{*}{$p_{\text {int }}$ Value $^{a}$} \\
\hline & Lacunar & Nonlacunar & $p$ Value & Lacunar & Nonlacunar & $p$ Value & \\
\hline \multicolumn{8}{|l|}{ Average BP } \\
\hline \multicolumn{8}{|l|}{$B P \leq 15 y$ before the event } \\
\hline Patients, $\mathbf{n}$ & 95 & 398 & & 214 & 1,378 & & \\
\hline Median (IQR) readings per patient, $n$ & $8(3-14)$ & $9(4-18)$ & & $14(7-32)$ & $20(9-35)$ & & \\
\hline Mean/SD SBP, mm Hg & $138.5 / 17.7$ & $133.3 / 15.0$ & 0.004 & $146.0 / 13.7$ & $145.7 / 13.9$ & 0.79 & 0.01 \\
\hline Mean/SD DBP, mm Hg & $84.1 / 9.6$ & $80.9 / 8.4$ & 0.001 & $81.4 / 7.2$ & $80.7 / 7.0$ & 0.14 & 0.02 \\
\hline \multicolumn{8}{|l|}{ BP $\leq 5$ y before the event } \\
\hline Patients, $\mathrm{n}$ & 87 & 361 & & 205 & 1,357 & & \\
\hline Median (IQR) readings per patient, $n$ & $4(1-11)$ & $5(2-11)$ & & $9(4-17)$ & $11(5-16)$ & & \\
\hline Mean/SD SBP, mm Hg & $142.6 / 18.8$ & $134.6 / 16.6$ & 0.0001 & $145.2 / 14.6$ & $143.9 / 14.6$ & 0.27 & 0.002 \\
\hline Mean/SD DBP, mm Hg & $85.2 / 9.7$ & $80.6 / 9.2$ & $<0.0001$ & $80.0 / 8.3$ & $78.5 / 7.8$ & 0.02 & 0.006 \\
\hline \multicolumn{8}{|l|}{$B P>5 y$ before the event } \\
\hline Patients, $\mathrm{n}$ & 82 & 347 & & 200 & 1,247 & & \\
\hline Median (IQR) readings per patient, $n$ & $4(2-7)$ & $4(2-10)$ & & $6(3-15)$ & $10(4-20)$ & & \\
\hline Mean/SD SBP, mm Hg & 133.0/15.1 & $131.6 / 16.1$ & 0.46 & $146.4 / 14.7$ & $146.9 / 15.9$ & 0.68 & 0.39 \\
\hline Mean/SD DBP, mm Hg & $82.6 / 9.4$ & $80.6 / 9.2$ & 0.08 & $82.8 / 8.0$ & $82.8 / 7.5$ & 0.98 & 0.08 \\
\hline \multicolumn{8}{|l|}{ BP variability ${ }^{b}$} \\
\hline Patients, $\mathbf{n}$ & 46 & 226 & & 164 & 1,123 & & \\
\hline \multicolumn{8}{|l|}{ SBP, mm Hg } \\
\hline Maximum, mean/SD & $173.7 / 26.6$ & $158.6 / 23.2$ & 0.0001 & $173.3 / 21.6$ & $171.7 / 23.4$ & 0.40 & 0.001 \\
\hline $\mathrm{CV}$, mean/SD, \% & $9.7 / 3.5$ & $9.4 / 4.3$ & 0.60 & 10.0/3.6 & $10.2 / 3.7$ & 0.42 & 0.38 \\
\hline$\geq 50 \%$ over $140 \mathrm{~mm} \mathrm{Hg,} \mathrm{n( \% )}$ & $30(65.2)$ & $83(36.7)$ & 0.0004 & $108(65.9)$ & $615(54.8)$ & 0.01 & \\
\hline$\geq 50 \%$ over $160 \mathrm{~mm} \mathrm{Hg,} \mathrm{n( \% )}$ & $10(21.7)$ & $12(5.3)$ & 0.0002 & $23(14.0)$ & $141(12.6)$ & 0.60 & \\
\hline$\geq 50 \%$ over $180 \mathrm{~mm} \mathrm{Hg}, \mathrm{n}(\%)$ & $2(4.3)$ & $2(0.9)$ & 0.08 & $3(1.8)$ & $16(1.4)$ & 0.69 & \\
\hline \multicolumn{8}{|l|}{ DBP, mm Hg } \\
\hline Maximum, mean/SD & $102.3 / 12.9$ & $94.2 / 11.2$ & $<0.0001$ & $94.7 / 11.4$ & $92.6 / 11.0$ & 0.03 & 0.003 \\
\hline CV, mean/SD, \% & $9.8 / 3.2$ & $9.4 / 3.5$ & 0.47 & 10.2/3.7 & $10.5 / 3.6$ & 0.37 & 0.30 \\
\hline$\geq 50 \%$ over $90 \mathrm{~mm} \mathrm{Hg}, \mathrm{n}(\%)$ & $10(21.7)$ & $34(15.0)$ & 0.26 & $15(9.1)$ & $49(4.4)$ & 0.01 & \\
\hline$\geq 50 \%$ over $100 \mathrm{~mm} \mathrm{Hg}, \mathrm{n}(\%)$ & $5(10.9)$ & $3(1.3)$ & 0.001 & $1(0.6)$ & $5(0.4)$ & 0.77 & \\
\hline$\geq 50 \%$ over $110 \mathrm{~mm} \mathrm{Hg}, \mathrm{n}(\%)$ & $1(2.2)$ & $0(0)$ & 0.03 & $0(0)$ & $1(0.1)$ & 0.70 & \\
\hline
\end{tabular}

Abbreviations: $\mathrm{BP}=$ blood pressure; $\mathrm{CV}$ = coefficient of variation; $\mathrm{DBP}=$ diastolic blood pressure; IQR = interquartile range; $\mathrm{SBP}=$ systolic blood pressure. ${ }^{a} p_{\text {int }}$ represents the interaction terms to test the difference in mean BP in lacunar vs nonlacunar between the 2 age groups.

${ }^{\mathrm{b}}$ Analysis limited to patients with at least 4 BP readings during the 5 years before the event.

78.5/7.8 $\mathrm{mm} \mathrm{Hg}, p=0.02$; table 2), the mean SBP taken $\leq 5$ years before the event also did not differ significantly between patients with lacunar and those without nonlacunar events (145.2/14.6 vs $146.9 / 14.6 \mathrm{~mm} \mathrm{Hg}, p=0.27$; table 2$)$, partly as a result of a J-shaped association at $\mathrm{BP}<110 / 70 \mathrm{~mm} \mathrm{Hg}$ (table 3). Sensitivity analyses were again consistent (table e-1-e-4, links.lww.com/WNL/A446). Moreover, when the time periods before the event were further divided, there was 
Figure 1 Mean (95\% confidence interval) blood pressure taken during different time periods before the index event in patients with acute lacunar vs nonlacunar events stratified by age
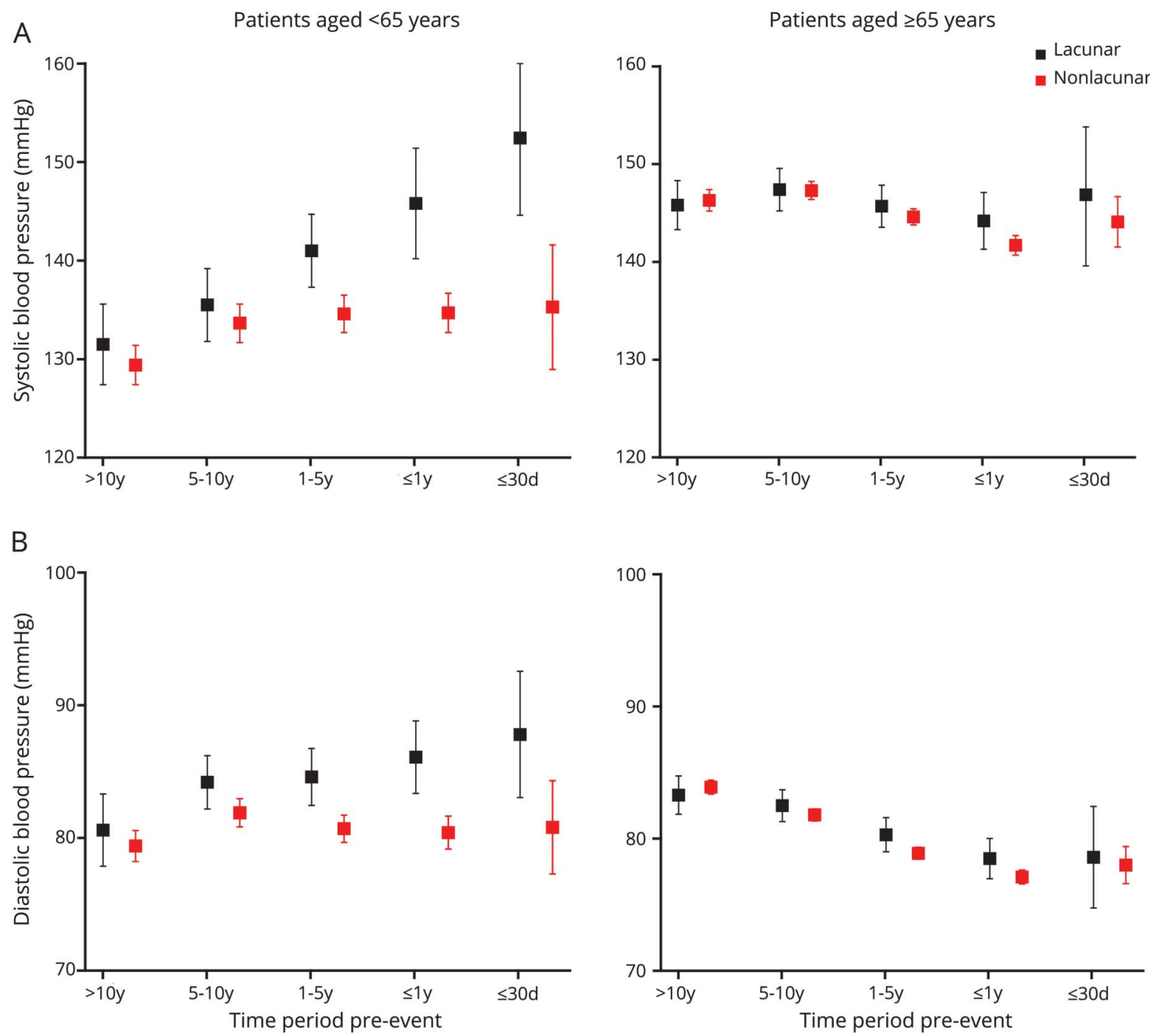

(A) Systolic blood pressure and (B) diastolic blood pressure.

no significant difference of BP in lacunar vs nonlacunar events with BP measured closer to the index event (figures 1 and 2; table e-4 and figures e-1 and e-2, links.lww.com/WNL/A445).

In patients $<65$ years of age, in addition to higher 5-year mean BP for patients with lacunar vs nonlacunar events, the maximum BP in the 5 years before the event was significantly higher in patients with lacunar events (SBP $173.7 / 26.6$ vs $158.6 / 23.2 \mathrm{~mm} \mathrm{Hg}, p=0.0001$; DBP $102.3 / 12.9$ vs $94.2 /$ $11.2 \mathrm{~mm} \mathrm{Hg}, p<0.0001$; table 2), with no difference in $\mathrm{CV}$ (SBP 9.7\%/3.5\% vs $9.4 \% / 4.3 \%, p=0.60$; DBP $9.8 \% / 3.2 \%$ vs $9.4 \% / 3.5 \%$; table 2). Compared to patients with nonlacunar events, those with lacunar events were also more likely to have persistently elevated $\mathrm{BP}$ at different target levels $(\geq 50 \% \mathrm{SBP}$ $>160 \mathrm{~mm} \mathrm{Hg}$ in the last 5 years in lacunar vs nonlacunar; odds ratio 4.95, 95\% confidence interval 1.99-12.31, $p=0.0002$; table 2). However, no similar differences were observed for patients $\geq 65$ years of age (table 2 ), apart from a marginally higher maximum DBP in patients with lacunar vs nonlacunar events $(94.7 / 11.4$ vs $92.6 / 11.0 \mathrm{~mm} \mathrm{Hg}, p=0.03$; table 2). Results were broadly similar for analyses including all 15 -year BP measurements (table e-5, links.lww.com/WNL/A446), stratified by premorbid use of antihypertensive treatment (table e-6), excluding TIA events (table e-7), and confined to incident events only (table e-8).

\section{Discussion}

In this population-based cohort of TIA and ischemic stroke with detailed records of premorbid $\mathrm{BP}$, we showed that the associations of BP and acute lacunar events differed by age. Patients with acute lacunar events at younger ages had significantly higher premorbid long-term average BP than those 
Figure 2 Temporal trends in the most recent SBP measurement during the year before (A) TIA and ischemic stroke or (B) ischemic stroke in lacunar vs nonlacunar events stratified by age

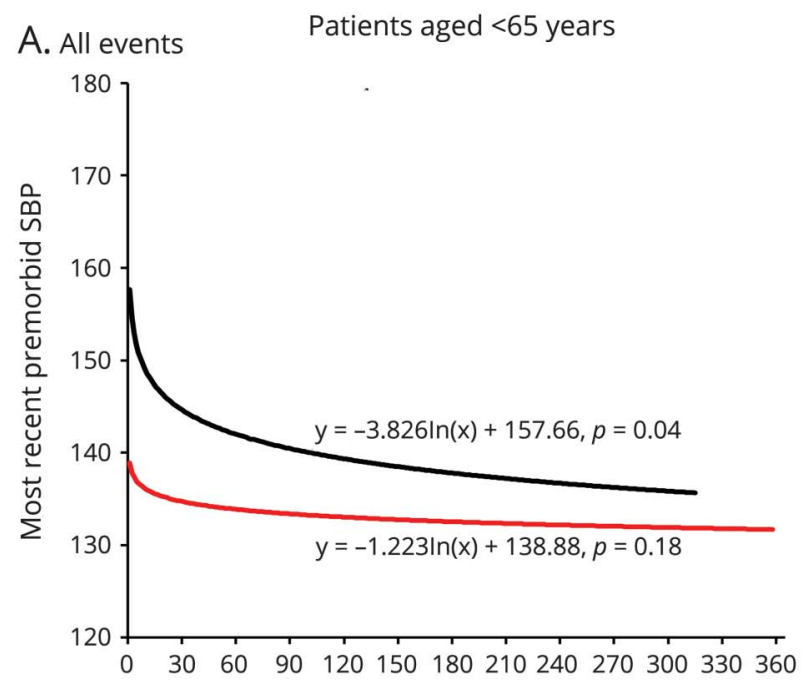

Patients aged $\geq 65$ years

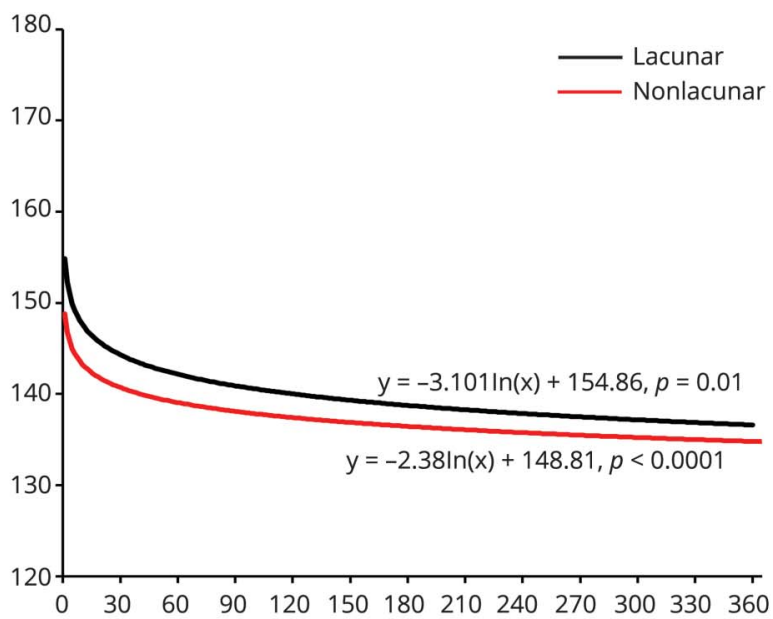

B. Ischemic stroke only
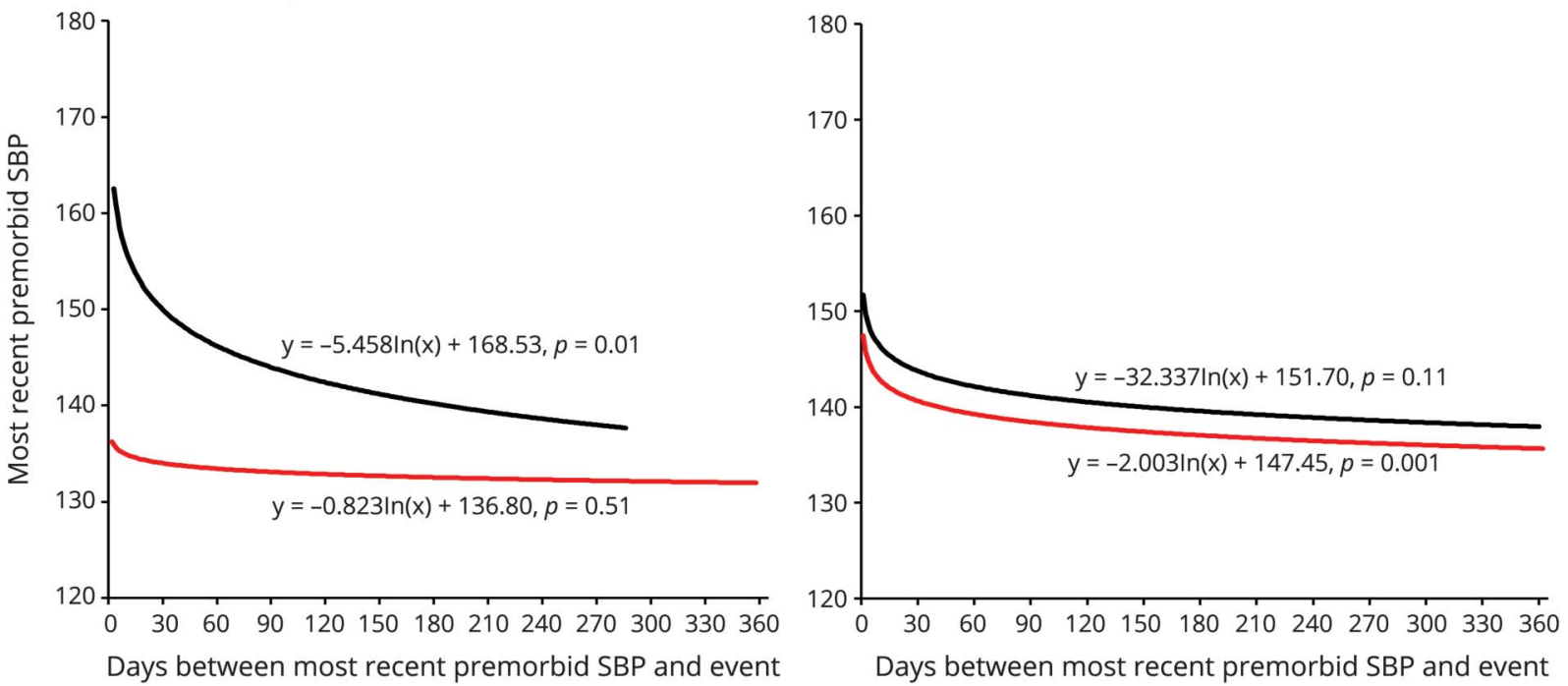

Trend lines are derived from a log-linear regression. SBP = systolic blood pressure.

with nonlacunar events, particularly in the 5 years before the index event, with further increases more immediately before the event. This group also had higher maximum premorbid $\mathrm{BP}$ and a higher prevalence of uncontrolled BP before the event than patients with nonlacunar etiology. In contrast, the associations of BP and acute lacunar events at older ages were more complex, with possibly different associations of SBP vs DBP and some evidence of a J shape.

Our findings support the hypothesis that recent BP level has a direct role in the etiology of acute lacunar events at younger ages, which is also consistent with previous autopsy studies (mean age $\approx 65$ years) that showed a strong association between hypertension and lacunar infarct ${ }^{17}$ and with the observation that lowering BP is most effective in preventing recurrent stroke in younger patients with recent lacunar infarct. $^{22}$ Of note, we also found the same prevalence of diagnosed hypertension in lacunar vs nonlacunar events, highlighting the fact that the crude prevalence of reported vascular risk factors is not always an adequate measure of risk ${ }^{23}$ and that multiple premorbid BP measurements may be necessary to assess true usual BP.

The findings that the difference in premorbid BP between lacunar and nonlacunar cases was most prominent for BP measurements taken closest to the index event, particularly in patients on antihypertensive treatment, probably reflect a failure to adequately control BP as a result of either treatment failure or noncompliance with treatment.

The diminished associations of BP and lacunar events at older ages are in accordance with a large cohort study that 
Table 3 Odds of lacunar vs nonlacunar events at different levels of premorbid mean BP stratified by measurement period and age

\begin{tabular}{|c|c|c|c|c|}
\hline \multirow[b]{2}{*}{ Mean, mm Hg } & \multicolumn{2}{|l|}{ Age $<65$ y } & \multicolumn{2}{|l|}{ Age $\geq 65$ y } \\
\hline & OR $(95 \% \mathrm{Cl})$ & $p$ Value & OR $(95 \% \mathrm{Cl})$ & $p$ Value \\
\hline \multicolumn{5}{|l|}{ SBP } \\
\hline \multicolumn{5}{|c|}{$\leq 1$ y before the event } \\
\hline$<110$ & $1.01(0.21-4.83)$ & 0.99 & $2.71(1.04-7.02)$ & 0.04 \\
\hline $110-139$ & Reference & - & Reference & - \\
\hline 140-159 & $1.22(0.62-2.38)$ & 0.57 & $1.27(0.87-1.87)$ & 0.22 \\
\hline$\geq 160$ & $5.94(2.54-13.87)$ & $<0.0001$ & $1.76(1.10-2.82)$ & 0.02 \\
\hline \multicolumn{5}{|c|}{$\leq 5 \mathrm{y}$ before the event } \\
\hline$<110$ & $0.31(0.04-2.42)$ & 0.27 & $1.86(0.52-6.68)$ & 0.34 \\
\hline $110-139$ & Reference & - & Reference & - \\
\hline $140-159$ & $1.57(0.93-2.64)$ & 0.09 & $1.36(0.98-1.89)$ & 0.07 \\
\hline$\geq 160$ & $3.55(1.67-7.54)$ & 0.001 & $1.31(0.83-2.07)$ & 0.24 \\
\hline \multicolumn{5}{|l|}{ DBP } \\
\hline \multicolumn{5}{|c|}{$\leq 1$ y before to event } \\
\hline$<70$ & $0.24(0.03-1.99)$ & 0.19 & $1.24(0.75-2.05)$ & 0.41 \\
\hline $70-79$ & Reference & - & Reference & - \\
\hline $80-89$ & $2.19(1.01-4.76)$ & 0.05 & $1.71(1.15-2.54)$ & 0.008 \\
\hline$\geq 90$ & $3.55(1.49-8.46)$ & 0.004 & $1.56(0.85-2.84)$ & 0.15 \\
\hline \multicolumn{5}{|c|}{$\leq 5 \mathrm{y}$ before the event } \\
\hline$<70$ & $0.17(0.02-1.30)$ & 0.09 & $1.17(0.71-1.94)$ & 0.53 \\
\hline $70-79$ & Reference & - & Reference & - \\
\hline $80-89$ & $1.75(0.97-3.14)$ & 0.06 & $1.42(1.01-1.98)$ & 0.04 \\
\hline$\geq 90$ & $2.47(1.23-4.94)$ & 0.01 & $2.22(1.33-3.70)$ & 0.002 \\
\hline
\end{tabular}

Abbreviations: $\mathrm{BP}=$ blood pressure; $\mathrm{Cl}=$ confidence interval; $\mathrm{DBP}=$ diastolic blood pressure; $\mathrm{OR}=$ odds ratio; $\mathrm{SBP}=$ systolic blood pressure .

also showed decreased associations of BP and stroke with age. $^{24}$ There are several potential explanations. First, we showed, at older ages, some evidence of a J shape for lacunar vs nonlacunar events at $\mathrm{BP}<110 / 70 \mathrm{~mm} \mathrm{Hg}$, suggesting that both hypertension and hypotension may play a role in acute lacunar events. However, only 26 patients $\geq 65$ years of age had a 1-year mean SBP $<110 \mathrm{~mm} \mathrm{Hg}$, so we were not powered to test this hypothesis reliably. Second, our findings support the hypothesis that atheromatous perforator occlusion is more common at older ages, often in association with intracranial stenosis, ${ }^{18}$ whereas acute hypertension induced lipohyalinosis predominates at younger ages. Finally, because hypertension is also a risk factor for atrial fibrillation and large artery atherosclerotic disease, which tend to predominate at older ages, hypertension is likely to be less specifically associated with lacunar stroke at older ages.
We found that compared to nonlacunar events, long-term and recent DBPs were also significantly associated with lacunar events, even at older ages. DBP is sometimes neglected since the shift of clinical focus to SBP in the 1990s. ${ }^{25}$ However, DBP is largely equally informative to SBP in predicting risks of stroke, ${ }^{2}$ particularly at younger ages, and higher DBP is independently associated with lacunes on brain imaging. ${ }^{11-13,26}$ Moreover, there is evidence of a specific association of DBP, independently of SBP, with white matter changes, ${ }^{27}$ microbleeds, ${ }^{28}$ retinal arteriolar narrowing, ${ }^{29}$ and cognitive decline ${ }^{30}$ indicating that DBP may be an important factor in small vessel disease more generally. ${ }^{31}$

In contrast to mean $\mathrm{BP}$, we did not find significant differences in premorbid BP variability in lacunar vs nonlacunar events at any age. Although BP variability is known to increase the risk of stroke more generally, ${ }^{32}$ it appears not to have a distinct 
role in acute lacunar events over and above its association with maximum $\mathrm{BP}$, which is consistent with the finding that withinvisit $\mathrm{BP}$ variability was not associated with recurrent stroke risk in patients with recent lacunar stroke in the Secondary Prevention of Small Subcortical Strokes (SPS3) trial. ${ }^{33} \mathrm{We}$ found slightly lower long-term BP variability in lacunar vs nonlacunar events at older ages, possibly reflecting the stronger associations of visit-to-visit BP variability and atrial fibrillation and atherosclerosis, ${ }^{32}$ which are the most common causes for nonlacunar stroke at older ages.

Although we consider the results to be valid, our study has limitations. First, the accuracy of BP can be affected by measurement error. However, inaccuracy of the measurement could not have biased our comparison of lacunar vs nonlacunar events because all measurements were made before the TIA or stroke. Second, a systematic protocol for recording premorbid BP was not possible, and we had to rely on measurements taken in routine clinical practice in primary care. However, this limitation again should not have biased our comparison of lacunar and nonlacunar events. Moreover, because our comparison was stratified by age, the number and timing of premorbid BP readings were also balanced between the groups. Third, the original TOAST classification incorporated etiologic assumptions of hypertension into the criteria for lacunar events. ${ }^{9}$ However, we did not include hypertension and diabetes mellitus in the criteria of our lacunar classification. Finally, we also applied the TOAST classification to classify TIAs. Although not originally developed for TIAs, the usefulness of the TOAST criteria in TIA has been validated. ${ }^{34}$ Moreover, our sensitivity analysis excluding TIAs showed consistent results.

Our findings have several implications. First, we showed that recent premorbid $\mathrm{BP}$ control is strongly related to acute lacunar events at younger ages, suggesting that BP plays a direct role in the etiology of small vessel disease at younger ages and highlighting the importance of timely control of BP after diagnosis. Second, DBP should not be neglected, particularly in young and middle-aged individuals, at least from the point of view of small vessel disease prevention. Third, more research is required to understand the more complex associations of BP and lacunar events at older ages. Finally, in studies of other risk factors in the etiology of white matter disease, microbleeds, and associated cognitive decline, our findings highlight the difficulty of excluding confounding by hypertension in the absence of detailed records of prior BP control.

\section{Author contributions}

Linxin Li collected data, did the statistical analysis and interpretation, and wrote and revised the manuscript. Sarah Welch and Sergei Gutnikov collected data. Ziyah Mehta did the statistical analysis. Peter Rothwell conceived and designed the overall study, provided study supervision and funding, acquired, analyzed and interpreted data, and wrote and revised the manuscript.

\section{Acknowledgment}

The authors are grateful to all the staff in the general practices that collaborated in the Oxford Vascular Study: Abingdon Surgery, Abingdon; Malthouse Surgery, Abingdon; Marcham Road Family Health Centre, Abingdon; The Health Centre, Berinsfield; Key Medical Practice, Kidlington; 19 Beaumont St, Oxford; East Oxford Health Centre, Oxford; and Church Street Practice, Wantage. They also acknowledge the use of the facilities of the Acute Vascular Imaging Centre, Oxford.

\section{Study funding}

OXVASC is funded by the National Institute for Health Research (NIHR) Oxford Biomedical Research Centre, Wellcome Trust, Wolfson Foundation, British Heart Foundation, and European Union's Horizon 2020 Research and Innovation Programme under grant agreement 666881,SVDs@ target. Dr. Rothwell is in receipt of an NIHR Senior Investigator Award. The views expressed are those of the authors and not necessarily those of the National Health Service, the NIHR or the Department of Health.

\section{Disclosure}

The authors report no disclosures relevant to the manuscript. Go to Neurology.org/N for full disclosures.

Received October 20, 2017. Accepted in final form February 12, 2018.

\section{References}

1. Stamler J, Stamler R, Neaton JD. Blood pressure, systolic and diastolic, and cardiovascular risks: US population data. Arch Intern Med 1993;153:598-615.

2. Lewington S, Clarke R, Qizilbash N, Peto R, Collins R. Age-specific relevance of usual blood pressure to vascular mortality: a meta-analysis of individual data for one million adults in 61 prospective studies. Lancet 2002;360:1903-1913.

3. Arima H, Murakami Y, Lam TH, et al. Effects of prehypertension and hypertension subtype on cardiovascular disease in the Asia-Pacific Region. Hypertension 2012;59:1118-1123.

4. Miura K, Nakagawa H, Ohashi Y, et al. Four blood pressure indexes and the risk of stroke and myocardial infarction in Japanese men and women: a meta-analysis of 16 cohort studies. Circulation 2009;119:1892-1898

5. Kolominsky-Rabas PL, Weber M, Gefeller O, Neundoerfer B, Heuschmann PU. Epidemiology of ischemic stroke subtypes according to TOAST criteria: incidence, recurrence, and long-term survival in ischemic stroke subtypes: a population-based study. Stroke 2001;32:2735-2740.

6. Woo D, Gebel J, Miller R, et al. Incidence rates of first-ever ischemic stroke subtypes among blacks: a population-based study. Stroke 1999;30:2517-2522.

7. Saposnik G, Caplan LR, Gonzalez LA, et al. Differences in stroke subtypes among natives and Caucasians in Boston and Buenos Aires. Stroke 2000;31:2385-2389.

8. Wang YL, Xu J, Zhao XQ et al. Association of hypertension with stroke recurrence depends on ischemic stroke subtype. Stroke 2013;44:1232-1237.

9. Jackson C, Sudlow C. Are lacunar strokes really different? A systematic review of differences in risk factor profiles between lacunar and nonlacunar infarcts. Stroke 2005;36:891-901.

10. Ohira T, Shahar E, Chambless LE, Rosamond WD, Mosley TH, Folsom AR. Risk factors for ischemic stroke subtypes: the Atherosclerosis Risk in Communities study. Stroke 2006;37:2493-2498.

11. Mast H, Thompson JLP, Lee SH, Mohr JP, Sacco RL. Hypertension and diabetesmellitus as determinants of multiple lacunar infarcts. Stroke 1995;26:30-33.

12. Hasegawa Y, Yamaguchi T, Omae T, Woodward M, Chalmers J; PROGRESS CT Substudy Investigators. Effects of perindopril-based blood pressure lowering and of patient characteristics on the progression of silent brain infarct: the Perindopril Protection Against Recurrent Stroke Study (PROGRESS) CT substudy in Japan. Hypertens Res 2004;27:147-156.

13. Spolveri S, Baruffi MC, Cappelletti C, et al. Vascular risk factors linked to multiple lacunar infarcts. Cerebrovasc Dis 1998;8:152-157.

14. Fischer U, Cooney MT, Bull LM, et al. Acute post-stroke blood pressure relative to premorbid levels in intracerebral haemorrhage versus major ischaemic stroke: a population-based study. Lancet Neurol 2014;13:374-384.

15. Emdin CA, Rothwell PM, Salimi-Khorshidi G, et al. Blood pressure and risk of vascular dementia: evidence from a primary care registry and a cohort study of transient ischaemic attack and stroke. Stroke 2016;47:1429-1435.

16. Guo Z, Viitanen M, Fratiglioni L, Winblad B. Low blood pressure and dementia in elderly people: the Kungsholmen project. BMJ 1996; 312: 805-808. 
17. Fisher CM. Lacunes: small, deep cerebral infarcts. Neurology 1965;15:774-784.

18. Wolters FJ, Schulz UG, Kueker W, Rothwell PM. Yield of routine MR angiography of the full extracranial and intracranial circulation in older Caucasian patients with TIA and minor ischaemic stroke: population-based study. Cerebrovasc Dis 2014;37 (suppl 1):211.

19. Rothwell PM, Coull AJ, Giles MF, et al. Change in stroke incidence, mortality, casefatality, severity, and risk factors in Oxfordshire, UK from 1981 to 2004 (Oxford Vascular Study). Lancet 2004;363:1925-1933.

20. Li L, Yiin GS, Geraghty OC, et al. Incidence, outcome, risk factors, and long-term prognosis of cryptogenic transient ischaemic attack and ischaemic stroke: a population-based study. Lancet Neurol 2015;14:903-913.

21. Adams HP Jr, Bendixen BH, Kappelle LJ, et al. Classification of subtype of acute ischemic stroke: definitions for use in a multicenter clinical trial: TOAST: Trial of Org 10172 in Acute Stroke Treatment. Stroke 1993;24:35-41.

22. White CL, Szychowski JM, Pergola PE, et al. Can blood pressure be lowered safely in older adults with lacunar stroke? The secondary prevention of small subcortical strokes study experience. J Am Geriatr Soc 2015;63: 722-729.

23. Howard G, Kissela BM, Goff DC, et al. Changes in the impact of stroke risk factors with age, and implications for stroke epidemiology in the elderly: the Reasons for Geographic and Racial Differences in Stroke (REGARDS) Study. Cerebrovasc Dis 2013;35:141.

24. Rapsomaniki E, Timmis A, George J, et al. Blood pressure and incidence of twelve cardiovascular diseases: lifetime risks, healthy life-years lost, and age-specific associations in 1.25 million people. Lancet 2014;383:1899-1911.

25. Williams B, Lindholm LH, Sever P. Systolic pressure is all that matters. Lancet 2008; 371:2219-2221.
26. Longstreth WT, Bernick C, Manolio TA, et al. Lacunar infarcts defined by magnetic resonance imaging of 3660 elderly people: the Cardiovascular Health Study. Arch Neurol 1998;55:1217-1225.

27. Marcus J, Gardener H, Rundek T, et al. Baseline and longitudinal increases in diastolic blood pressure are associated with greater white matter hyperintensity volume the Northern Manhattan Study. Stroke 2011;42:2639-2641.

28. Klarenbeek P, van Oostenbrugge RJ, Rouhl RPW, Knottnerus ILH, Staals J. Higher ambulatory blood pressure relates to new cerebral microbleeds 2-year follow-up study in lacunar stroke patients. Stroke 2013;44:978-983.

29. Leung H, Wang JJ, Rochtchina E, Wong TY, Klein R, Mitchell P. Impact of current and past blood pressure on retinal arteriolar diameter in an older population. J Hypertens 2004;22:1543-1549.

30. Thorvaldsson V, Skoog I, Hofer SM, et al. Nonlinear blood pressure effects on cognition in old age: separating between-person and within-person associations. Psychol Aging 2012;27:375-383.

31. Guo XX, Pantoni L, Simoni M, et al. Blood pressure components and changes in relation to white matter lesions a 32-year prospective population study. Hypertension 2009;54:57-62.

32. Rothwell PM, Howard SC, Dolan E, et al. Prognostic significance of visit-to-visit variability, maximum systolic blood pressure, and episodic hypertension. Lancet 2010; 375:895-905.

33. Field TS, Kristopher P, McClure LA, et al. The impact of blood pressure variability on stroke recurrence: the SPS3 trial. Stroke 2014;45:A95.

34. Amort M, Fluri F, Weisskopf F, et al. Etiological classifications of transient ischemic attacks: subtype classification by TOAST, CCS and ASCO: a pilot study. Cerebrovasc Dis 2012;33:508-516. 


\title{
Time course of blood pressure control prior to lacunar TIA and stroke
}

\author{
Population-based study
}

\author{
Linxin Li, DPhil, Sarah J.V. Welch, RGN, Sergei A. Gutnikov, DPhil, Ziyah Mehta, DPhil, \\ and Peter M. Rothwell, FMedSci, on behalf of the Oxford Vascular Study \\ Cite as: Neurology ${ }^{\circledR}$ 2018;90:e1732-e1741. doi:10.1212/WNL.0000000000005526
}

\begin{abstract}
Correspondence
Peter M. Rothwell

peter.rothwell@

ndcn.ox.ac.uk
\end{abstract}

\section{Study question}

What are the age-specific temporal trends in blood pressure associated with acute lacunar vs nonlacunar transient ischemic attack and stroke?

\section{Summary answer}

High premorbid blood pressure (BP) was strongly temporally associated with acute lacunar events in individuals $<65$ years of age.

\section{What is known and what this paper adds}

Hypertension is a well-established risk factor for stroke; yet, there is conflicting evidence about the role of BP in lacunar stroke. We previously found that recent increases in premorbid BP were more highly associated with deep rather than lobar intracerebral haemorrhage; the present study shows that this is also true for lacunar vs nonlacunar ischemic stroke.

\section{Participants and setting}

The analysis included 2,085 consecutive cases with first-time TIA $(n=835)$ or ischemic stroke $(n=1,250)$ from the Oxford Vascular Study, a population-based study of acute vascular events in Oxfordshire, UK.

\section{Design, size, and duration}

Fifteen-year premorbid BP readings were analysed as long-term average values and long-term variability in patients with lacunar and non-lacunar events. The analysis was stratified by age $(<65$ and $\geq 65$ years). Analyses involved examining between-group differences in the frequency of previous hypertension and premorbid antihypertensive use, trends and averages of longterm $\mathrm{BP}$, and long-term maximum $\mathrm{BP}$ and variability.

\section{Main results and the role of chance}

Of 2,085 patients, 309 had lacunar events. There was no difference in diagnosed hypertension between the lacunar and nonlacunar event groups; however, 15-year premorbid BP was higher in the lacunar event group for patients $<65$ years, primarily due to $\mathrm{BP}$ elevations during the 5 years preceding
Table Premorbid average blood pressure (mean blood pressure) in younger (<65 years) patients with lacunar vs nonlacunar events

\begin{tabular}{|c|c|c|c|}
\hline \multirow[b]{2}{*}{ Average blood pressure } & \multicolumn{3}{|l|}{$<65 y$} \\
\hline & Lacunar & $\begin{array}{l}\text { Non- } \\
\text { lacunar }\end{array}$ & $\begin{array}{l}p \\
\text { Value }\end{array}$ \\
\hline \multicolumn{4}{|l|}{$\mathrm{BP} \leq 5$ years prior to the event } \\
\hline No. of patients & 87 & 361 & \\
\hline $\begin{array}{l}\text { Median (IQR) readings per } \\
\text { patient }\end{array}$ & $4(1-11)$ & $5(2-11)$ & \\
\hline Mean/SD SBP, mm Hg & $142.6 / 18.8$ & $134.6 / 16.6$ & 0.0001 \\
\hline Mean/SD DBP, mm Hg & $85.2 / 9.7$ & $80.6 / 9.2$ & $<0.0001$ \\
\hline
\end{tabular}

Abbreviations: $\mathrm{BP}=$ Blood pressure; $\mathrm{DBP}=$ Diastolic blood pressure; $\mathrm{IQR}=$ Interquartile range; $\mathrm{SBP}=$ Systolic blood pressure; $\mathrm{SD}=$ Standard deviation.

events. There was also a rising trend in elevated BP leading up to events $(p=0.006)$ and higher maximum BP in the lacunar group for patients $<65$ years. No such differences were identified in patients $\geq 65$ years.

\section{Bias, confounding, and other reasons for caution}

$\mathrm{BP}$ measurements were potentially subject to measurement error. Additionally, there was no systematic protocol for recording premorbid BP as measurements were taken at routine visits.

\section{Generalizability to other populations}

The study results are generalizable to young ( $<65$ years) patients with first-time TIA or stroke.

\section{Study funding/potential competing interests}

The Oxford Vascular Study was funded by the National Institute for Health Research, Oxford Biomedical Research Centre, Wellcome Trust, Wolfson Foundation, British Heart Foundation, and the European Union's Horizon 2020 research and innovation programme. Go to Neurology.org/N for full disclosures. 


\section{Neurology}

\section{Time course of blood pressure control prior to lacunar TIA and stroke: Population-based study \\ Linxin Li, Sarah J.V. Welch, Sergei A. Gutnikov, et al.}

Neurology 2018;90;e1732-e1741 Published Online before print April 18, 2018

DOI 10.1212/WNL.0000000000005526

\section{This information is current as of April 18, 2018}

\section{Updated Information \& Services \\ Supplementary Material}

\section{References}

Citations

Subspecialty Collections

Permissions \& Licensing

Reprints including high resolution figures, can be found at: http://n.neurology.org/content/90/20/e1732.full

Supplementary material can be found at: http://n.neurology.org/content/suppl/2018/05/10/WNL.0000000000005 526.DC1

This article cites 34 articles, 14 of which you can access for free at: http://n.neurology.org/content/90/20/e1732.full\#ref-list-1

This article has been cited by 1 HighWire-hosted articles: http://n.neurology.org/content/90/20/e1732.full\#\#otherarticles

This article, along with others on similar topics, appears in the following collection(s):

\section{All Cerebrovascular disease/Stroke}

http://n.neurology.org/cgi/collection/all_cerebrovascular_disease_strok $\mathrm{e}$

Information about reproducing this article in parts (figures,tables) or in its entirety can be found online at:

http://www.neurology.org/about/about_the_journal\#permissions

Information about ordering reprints can be found online:

http://n.neurology.org/subscribers/advertise

Neurology ${ }^{\circledR}$ is the official journal of the American Academy of Neurology. Published continuously since 1951, it is now a weekly with 48 issues per year. Copyright Copyright ( 2018 The Author(s). Published by Wolters Kluwer Health, Inc. on behalf of the American Academy of Neurology.. All rights reserved. Print ISSN: 0028-3878. Online ISSN: 1526-632X.

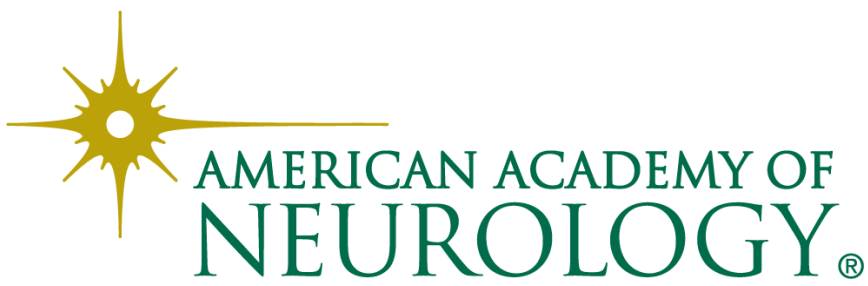

